\title{
Mordacidad e inocencia: Papelucho como documento de las clases medias en Chile (1947-1974)
}

\author{
Sharpness and innocence: Papelucho as a document of Chilean \\ middle classes (1947-1974)
}

\author{
Azun Candina Polomer \\ Universidad de Chile \\ azun@u.uchile.cl
}

\begin{abstract}
Resumen: El artículo analiza la serie de novelas cortas Papelucho, de la autora Esther Huneeus, como documento histórico que da cuenta de una mirada crítica sobre los cambios y transformaciones de la sociedad chilena durante el siglo XX, y particularmente de las contradicciones y tensiones de las clases medias en formación durante la segunda mitad del siglo.
\end{abstract}

Palabras clave: clase media, Papelucho, historia de Chile.

\begin{abstract}
The article analyzes the series of short novels Papelucho, by Esther Huneeus, as a historical document that accounts for a critical view at the changes and transformations of Chilean society during the twentieth century, and particularly the contradictions and tensions of the raising middle classes during the second half of that century.
\end{abstract}

Keywords: middle class, Papelucho, Chilean history.

Recibido: 09/08/2019

Aceptado: 25/09/2020

\section{Los documentos literarios y la historiografía de las clases medias para la historia chilena del siglo XX}

La incorporación de las narrativas literarias es particularmente relevante para el estudio de las clases medias latinoamericanas durante el siglo XX. Su capacidad para describir e interpretar la complejidad de la vida cotidiana es del mayor valor para comprender estos grupos que desafían las definiciones u oposiciones binarias de ricos y pobres y explotadores y explotados, y que obligan a los investigadores a recordar que las estructuras sociales son relacionales; si la pirámide social es útil como esquema pedagógico, la realidad social no es un dibujo geométrico y no puede ser 
reducida a él. Los estudios históricos y sociológicos más recientes han evitado una aproximación positivista que mide la 'clasemediedad' solamente en términos de categorías ocupacionales, niveles de ingreso o patrones de consumo, pero ello no ha borrado el hecho de que la clase media ha sido históricamente caracterizadas por 'una sobreabundancia de significados' que hace al concepto ambiguo, impreciso y poco útil como categoría de análisis; sin formaciones políticas o colectivas propias, algunos autores han concluido que la clase media es una mera abstracción, una metáfora o un instrumento retórico, "con demasiadas agendas políticas que previenen —o descalifican - cualquier proyecto específico de clase" (Lopez y Weinstein 20), y cuyo sentido ha cambiado profundamente desde su concepción europea original (Adamovsky 10). Quizás la influencia de Marx obturó y sigue obturando aún hoy a los análisis de las clases medias, dado que el autor subestimó su papel en la elaboración de una teoría de clases, y que evidentemente no pudo prever el espectacular desarrollo de esos grupos 'intermedios' - pequeños y medianos propietarios, profesionales y empleados y obreros calificados- en el siglo XX (Visakovsky y Garguin 15). En el presente texto no pretendemos ahondar en esa discusión de por sí extensa, pero sí destacar el carácter ambiguo de las clases medias, no como una suerte de defecto a evitar o simplificar, sino como un problema interesante en sí mismo sobre la construcción y la relación entre las clases sociales contemporáneas.

Dentro de ese marco, el interés por Papelucho como documento de época no fue casual. Desde 1947 hasta 1974, la escritora chilena Esther Huneeus Salas (1902-1985), perteneciente a una familia de la clase alta chilena, publicó doce libros de la serie Papelucho, bajo el pseudónimo de Marcela Paz. Durante décadas, los diarios de Papelucho han formado parte de las lecturas escolares chilenas y llevan hasta la actualidad decenas de reediciones y reimpresiones. Presentados en formato de diario de vida, los libros de Papelucho relatan en primera persona las peripecias de un niño santiaguino de ocho años, que vive con sus padres, su hermano mayor Javier, la empleada doméstica Domitila y —a partir del volumen de 1958, Papelucho en la Clínica - una hermana menor, Jimena del Carmen, o 'la Jí. Su madre es dueña de casa, su padre trabaja en una empresa petrolera (probablemente la ENAP, Empresa Nacional del Petróleo) y, como veremos, el niño Papelucho es parte de una vida cotidiana en la que concurren personas de distintos grupos sociales, pero donde la autora sitúa a la familia en una suerte de clase media profesional que se distingue y auto-distingue claramente de los sectores populares y que tiene vínculos con la clase alta tradicional, pero que tampoco es parte de ella.

Papelucho, a diferencia de otros personajes de la literatura para niños y jóvenes, no tiene poderes sobrenaturales ni viaja a territorios fantásticos. Se mueve en un Chile bastante más prosaico, de papas con arroz, ratones en los entretechos y tías con verrugas. Desde ese punto de vista, es comparable a Mafalda, de Quino: otra 
niña aguda y crítica e hija de una familia de clase media urbana preocupada de los gastos, el auto nuevo o las plantas de interior, que desde una construida mirada infantil analiza el mundo a su alrededor (Cosse 33). A diferencia de ella, Papelucho no tiene una postura política evidente: sus juicios sobre la sociedad chilena pueden definirse como críticos, pero no desde una postura política abierta, sino desde una mordacidad encubierta de inocencia. Proponemos, así, que Esther Huneeus escribió en dos registros o niveles. Uno específicamente 'infantil', donde Papelucho imagina que habla con extraterrestres, rompe floreros y teléfonos y se esconde enfurruñado en su habitación a escribir su diario. El segundo registro, entretejido con el otro y disimulado entre las trastadas de un chico desobediente, es una crónica aguda y burlona de la vida privada chilena y sus cambios durante buena parte del siglo XX, y particularmente de ese grupo intermedio entre los pobres de solemnidad y los ricos, que se ha llegado a conocer como la clase media. Es a ese segundo registro donde apunta este texto.

\section{La tensa vida económica del mediopelo social}

Una de las características más constantes de Papelucho y su familia es la permanente precariedad económica en la que viven, la que se explica por los gustos y debilidades más bien suntuarias de sus padres y los problemas que les acarrean. En el primer libro de la serie, la familia va de vacaciones a Viña del Mar, donde los padres derrochan sus haberes en el Casino de juegos de la ciudad y se angustian por las cuentas impagas, en una situación que se extiende a su círculo de amigos. Relata Papelucho:

No me puedo dormir pensando en lo terrible que es la pobreza. Quiero decir que hay un señor Ruletero que se queda con toda la plata de mi papá y a veces con la de mi mamá, y lo más raro es que nadie hace nada por tomarlo preso. . . Parece que hace lo mismo con todo el mundo, porque ayer en la comida la tía Lala decía que ella le había dejado en el mes miles de pesos y la tía Ema que a ella le había quitado algunos, y así a cada una. . . Mi papá se queja porque mi mamá paga las cuentas o compra comida y mi mamá se queja porque el papá vuelve a lo del señor Ruletero, y se va armando la pelea. El dice que va a buscar lo que dejó y mi mamá dice que es sólo para que le saquen más. Y después, cuando él por fin decide que no irá, entonces llama a la mamá cualquier amiga y se va con ella. Después vuelve llorando, reclama de su poco carácter y habla mal de ella misma, etc., y mi papá sale furioso dando un portazo. (Papelucho 20).

El anterior es solo un ejemplo de las numerosas situaciones en que la familia de Papelucho revela el conflicto entre ciertos hábitos y formas de vivir, y los ingresos 
que no alcanzan para ello. Rematan sus bienes y luego vuelven a comprarlos, tienen una empleada doméstica — la Domitila - a la que a veces no pueden pagar y la madre de Papelucho trata de venderle a esa misma empleada un abrigo 'a plazos' cuando se queda sin dinero, pero al recibir una herencia, se van de paseo a Estados Unidos (Papelucho Casi Huérfano, 1951). El padre de Papelucho sueña con ser diputado o empresario, pero duermen en un taxi cuando un temblor daña su casa, porque no pueden pagar un hotel:

Resulta que el famoso temblor no botó ninguna casa ni cosa, sino que la de nosotros, que por suerte no es nuestra. Es de un señor propietario. . . Como los hoteles son muy caros la mamá decidió que dormiríamos en un taxi. Costó harto convencer al papá y al taxista, pero la mamá se las arregla para salir con su idea, y así nos instalamos frente a la puerta de calle, creo que para verla caer. (Papelucho y el Marciano 11)

La autora dibuja así un tipo particular de pobreza, que no es la indiscutible de los verdaderos pobres, sino una suerte de inestabilidad que a la vez se muestra o se oculta según las circunstancias, y donde la carencia se maneja a partir de estrategias como el crédito y la ayuda de la familia. Así la relata el personaje:

El otro día mi mamá le decía a alguien que estamos en la miseria y trataba de llorar o cosa por el estilo y a mí me dio mucha pena pensar que esto es la miseria, aunque no se nota mucho. Porque algunos creen que la miseria es con frío y harapos y hambre, pero en realidad hay de todo igual que antes, lo único es que eso que hay es 'a la cuenta'. (Papelucho Casi Huérfano 12)

Quizás la aventura donde más claramente se refleja esa doble narrativa de Marcela Paz es en Papelucho Misionero, de 1966. La familia viaja a África porque el padre de Papelucho ha sido enviado allí por la compañía en que trabaja. Mientras Papelucho fantasea con conocer la selva, evangelizar a los africanos y cazar con arco y flecha, el padre de Papelucho se asocia con un contrabandista de diamantes y deja su trabajo. Todo va mal, y la familia termina abandonada en una situación peor que la chilena, porque en otro continente no existen las redes de apoyo y ayuda locales:

Uno puede estar acostumbrado a ponerse pobre de repente en Chile, y puramente se nota en que la gente rezonga cuando se acaba el arroz, se quiebra un vidrio o cosa por el estilo, pero quedar pobre en el África es requete distinto. Porque no hay ni un pariente, ni almacenero conocido. . . el dueño del Hotel nos trata como si fuéramos ladrones, y nadie nos saluda. Dice el Botones que ahora somos 'aventureros' y que vivimos con una cuestión que se llama 'crédito’. (Papelucho Misionero 110) 


\section{Las relaciones y distancias con otros grupos sociales}

La segunda característica de estos textos es el relato que hace del contacto de Papelucho y su familia con otros grupos sociales, ahondando en una realidad que los estudios sociológicos o históricos sobre las clases sociales no abordan con frecuencia: esas relaciones entre personas de distintos orígenes y culturas sociales en la vida cotidiana, y no solamente en los conflictos de clase y claramente políticos. Hacia abajo y hacia arriba, por definirlo de alguna manera, Papelucho y su familia establecen distancias y comprensiones diferenciadas en sus encuentros y su convivencia diaria, que aquí se juzgan como específicas de ese contradictorio mediopelo social.

Los sectores populares chilenos están representados en las novelas a partir de la empleada Domitila, personajes ocasionales como diareros y mendigos y los dos niños que se hacen amigos de Papelucho, el Chirigüe ${ }^{1}$ y el Chorizo. Según su biógrafa, Esther Huneeus incluyó a esos niños en las novelas por la influencia de los sacerdotes Mariano Puga — quien además era su sobrino- y Alberto Hurtado, fundador del Hogar de Cristo (Larraín 28). Nuevamente y entrelazada con las aventuras infantiles del protagonista, la autora presenta una imagen de los pobres donde se resaltan las diferencias con Papelucho y su familia, no solamente en términos materiales, sino de formas de vivir y hablar y de relacionarse con el conjunto de la sociedad. Niños como el Chirigüe y el Chorizo no van al colegio, no tienen un nombre propio, solo esos apodos, y viven en un ambiente donde la violencia y el sufrimiento se presentan como naturalizados y parte de su cotidiano, como se describe en el siguiente párrafo, cuando Papelucho va a la población marginal donde vive el Chirigüe:

—Quiero ver tu casa — le dije al Chirigüe.

-Es un rancho por allá... - y me apuntó con la pera un montón de casuchas hechas de palos, cartones, latas y sacos.

La cuestión es que lo convencí de que me la mostrara y fuimos a verla. La población era como una cancha de fútbol, pero sin cancha y no tiene ningún peligro. Son toda gente conocida. Y hay que caminar miles de kilómetros al sol y pasar un zanjón lleno de cáscaras de sandía. El Chirigüe me contó que ahí se ahogó una guagua y también siete mujeres de amor. Hay un árbol viejo sin ninguna rama porque se usan de leña y hay un basural inmenso que sirve para encontrar cosas perdidas y juntar latas, papeles, trapos que se venden, etc. Y lo que no sirve se vende como tierra de hoja. Así que no importa que sea un poco fétido porque es como una verdadera mina. (Papelucho Detective 3 )

1 El Chirihue o Chirigüe es el nombre mapuche del Sicalis luteola, pájaro de plumaje amarillo verdoso y tamaño pequeño que habita en América del Sur y Central. 
Allí, en el mundo del Chirigüe, Papelucho es visto como un intruso: es un pije, un niño rico que se ha colado en su mundo. El Chirigüe vive con una tía y su marido, el Orocimbo, que esperan que traiga dinero de sus correrías por la ciudad. El trato y el habla de 'esas personas' es diferente a como habla Papelucho y su familia:

—Pelusa... que te llevai palomillando en vez de hacer lo que te mandan —le dijo [la tía].

—Pero si jui onde me dijo —alegó el Chirigüe.

- ¿Y cuál es que lo trajiste?

-Pero si no estaba el julano...

- ¿Y quién te manda a ponerte a jugar con este pijecito?

—Pero si apenita llegué no má...

— ¿Trajiste algo pa'l desayuno?

El Chirigüe se dio vuelta los bolsillos rotos y se rascó un pie con el otro. La tía le dio otro coscacho y empezó a hablar de que no tenía ni azúcar para una agüita ni pan duro. (Papelucho Detective 2)

A Papelucho, aventurero y curioso, le molesta el rechazo hacia su persona. Vende su polera y con eso compran azúcar y pan para llevarle a la tía, y además le dan una polera usada: "me quedaba chica y rota pero ya no me dirían 'pijecito"' (Papelucho Detective 11), declara Papelucho. Los dos niños, además, presencian una dura riña entre dos hombres en la población, y Papelucho comenta: "había un tremendo boche en la puerta de un rancho y un hombre le pegaba a otro y una mujer gritaba como una verdadera radio. A nadie le importaba mucho porque parece que en esta población la gente discute asî" ${ }^{2}$ (Papelucho Detective 11).

En términos de género, son destacables también las diferencias que Papelucho hace entre las mujeres como su madre, que es descrita como una señora linda, 'nerviosa', elegante y que no puede quedarse sin servicio doméstico (Papelucho 20), y la Domitila, que tiene 'pelo de alambre', es 'chinchosa' y gorda y está sometida a peligros y miedos propios de su condición de pobreza. La Domitila es parte de la familia y de los afectos de Papelucho, pero al mismo tiempo es un personaje que puede volverse peligroso y poco confiable. Dice Papelucho, cuando ocurre un robo en la casa y ha estado involucrado un novio de Domitila:

Resulta que el robo salió en el Vea y en las Últimas y también salió el retrato de la Domi. Y parece que para un pobre salir en el diario es todo lo contrario que para un rico, porque es terrible. Y también a ella la han hecho ir a decla-

2 El destacado es nuestro. 
rar. Y todo lo que ella dice sale en el Vea. Y la Domi cree que el Cloro la va a matar un día por haber declarado. ${ }^{3}$ (Papelucho Detective 41)

Algo similar ocurre con la señorita Mafalda, una profesora primaria rural que aparece en Papelucho casi huérfano, y que le hace clases cuando sus padres están de viaje en Estados Unidos. La señorita Mafalda es retratada de manera a la vez burlona y compasiva: Papelucho aprecia a esta solterona que 'silba con la ese y le sale airecito con olor a choclo’ lleva veinte años esperando a un novio 'muy pituco' que 'lo perdió por otra mujer', y se arregla todos los días por si acaso vuelve el novio (Papelucho casi huérfano 38). La descripción que se hace en el volumen de la vida, algo precaria y anticuada de la señorita Mafalda, marca diferencias con la familia de Papelucho, más urbana y moderna, y también con la tía Rosarito, con quien vive Papelucho en esos momentos:

La señorita Mafalda tiene unos retratos en marco de terciopelo y unos cojines con gato, hechos de alfombra, con mucha pelusa, y un reloj con cien rubíes. También tiene dos coronas en las muelas y los colmillos forrados en nylon y se va a poner un puente este otro año. . . Me da mucha pena que ella tenga que trabajar y también le hace bien conversar y descansar y sirve para conocernos. Ella quiere que le encargue medias de nylon a mi mamá y se las mande en una revista, porque así no pagan derechos. Y hoy me contó que la tía Rosarito tiene muchos millones, pero se hace la pobre para que no le pidan plata en la parroquia. (Papelucho Casi Huérfano 39).

Pues junto a esos personajes del mundo pobre urbano y rural, Papelucho y su familia también se relacionan con personas con dinero o más dinero que su familia nuclear, como la tía Rosarito, propietaria rural; el profeta Adalberto Rubilar, un magnate minero y algo trastornado que aparece en Papelucho en la Clínica, de 1958; y el Diputado, personaje de Papelucho Perdido, de 1962. Se trata de personajes diferentes entre sí, pero se destaca que la relación que Papelucho y su familia genera con ellos es tensa: por una parte, hay admiración y cierta envidia, como en la cita siguiente, cuando Papelucho se impresiona con todos los bienes y la comida que hay en la casa del Diputado, que no hay en su propia casa:

Llegamos a una casa macanuda, con todo, copas de Campeonato, paragüera, radio, espuelas, sopapo, extinguidor de incendio, estiladera, molino de agua y de café y montones de cosas nunca vistas. La señora Bebé a cada rato decía 'mijito' [al Diputado] y yo creía que era a mí, porque cómo iba a pensar que a ese tremendo diputado le iba a decir así, ni tampoco creía que él necesitaba

3 El destacado es nuestro. 
comer esas cosas para el desayuno. Porque nos dieron: huevos fritos, queque, choclos con mantequilla, mortadela, café con leche y una cuestión que se llama Natre y ciruelas con crema de postre. Yo habría querido ser del porte del Dipu para comer tanto como él. (Papelucho Perdido 11).

En el volumen Papelucho en la clínica, Papelucho es internado y operado de apendicitis por error. En el hospital se hace amigo de un anciano solitario — que bautiza como el Profeta Elías - al que llega a querer como a un abuelo y desea llevar a su casa. Sus padres lo rechazan, hasta que se descubre que el anciano en realidad es Adalberto Rubilar, un magnate de la minería:

-Así como a usted le nació una guagua en el Hospital, a mí me nació un abuelo. Y hay que llevarlo a vivir con nosotros. ¡Qué bueno, no!

Mi mamá me miró un poco raro y a papá le dio como tos. . Subimos al cacharro y al pasar por una tienda de autos, al señor Rubilar se le ocurrió cambiarlo por otro nuevo más grande y cómodo. Sacó su cheque, cambiamos las maletas, dejamos ahí el aparato viejo y seguimos viaje a Concón muy felices en la Ranchera modelo Lunik 2000. La Lunik que le regaló al papá el Profeta tenía un olorcito a nuevo tan rico que yo ni sabía cuál me gustaba más: si el olor del mar, o ese. . . Y el señor Rubilar se hizo tan amigo de mi mamá y mi papá hablando todo el tiempo de gente antigua y andaban como buscando de ser parientes de alguna manera, aunque nunca resultó, así que yo mientras tanto iba haciendo mis planes para pasarlo regio. (Papelucho en la Clínica 29)

No se debe dejar pasar la frase 'y andaban buscando ser parientes de alguna manera', en la cita previa: da cuenta de la importancia que en las novelas las relaciones de parentesco como formas de cercanía y confianza, que en la familia de Papelucho se dan - y se buscan — hacia arriba, y no hacia abajo. En sus relatos y a pesar de los comentarios frecuentes sobre los problemas económicos, Papelucho identifica a su familia con los ricos, mientras a otros les toca el papel de pobres. Él mismo, como mencionamos, puede sumarse al segundo grupo, especialmente en oposición y crítica a sus padres, cuando no comparten sus raptos de generosidad:

Me voy a la montaña, donde nadie me insulte y me desentienda. Mi padre es cruel y me aborrece. Todo porque le di uno de sus trajes al pobre Buzeta, que tiene ocho hijos. Me dijo que yo había tomado lo ajeno. Eso no es verdad, porque lo de los padres de uno es también de uno. Al principio me sentí ladrón y me dieron ganas de morirme, pero después pensé y vi que yo tenía razón y él no. Los ricos no saben lo que es pobreza. Yo sé. (Papelucho 10) 
Ahora que no tengo útiles para hacer mis experimentos, tengo que hacerlos con las cosas de otro. Por eso le pedí a Miguel, el jardinero, que me diera un alicate y un alambre. Y tuve que regalarle dos corbatas de mi papá. Papá tiene demasiadas corbatas, y eso es como avaricia, y también hace que Miguel se ponga comunista. (Papelucho 4)

Las posturas del relato en términos políticos también corresponden a modelos valóricos conservadores. En Papelucho Historiador (1955), donde el niño cuenta la historia de Chile, se relevan particularmente el valor de la iglesia y la evangelización de los 'indios' y la heroicidad de los conquistadores españoles y los patriotas de la guerra de independencia (Papelucho Historiador). Asimismo, y en los últimos volúmenes de la serie publicados en la década de 1970, hay un relato burlón y ridiculizador de los cambios de la cultura juvenil, como en el caso de Mi hermano Hippie, de 1971. Tras sus vacaciones, Javier, el hermano mayor de Papelucho, llega a la casa y sus padres se encuentran con el antiguo cadete de la Escuela Naval se ha transformado en hippie. La mirada infantil hace de ese hermano rupturista, una suerte de payaso:

Traía el pelo largo y crespito, un cintillo a lo indio, pantalón verde con lagartijas blancas y en lugar de camisa, una cadena de lavatorio de la que colgaba una estrella de mar que se enredaba en unos pelos colorines que le habían salido en el pecho. En lugar de zapatos sus patas gordas y casposas se agrandaban silenciosas en el suelo y en cada uña de los dedos del pie tenía pegado un caracol de algún color catalíptico. (Mi hermano Hippie 7)

El padre de Papelucho se horroriza, su madre se desmaya y la hermanita Jimena tiene un ataque de risa. Javier, humillado, se encierra en el baño y luego desaparece. Por supuesto, Papelucho se dedica a la tarea de buscarlo y a soñar que será un héroe por encontrar al hermano transformado. Javier, tras unos días fuera de casa, empieza a dejarle mensajes escondidos a Papelucho para que le consiga dinero y comida. Finalmente, vuelve al hogar familiar y se acuesta en su cama, y Papelucho lo interroga:

—Menos mal que volviste — le dije_-, el Chori y yo empezábamos a aburrirnos.

-Yo también me aburría — confesó metiéndose en la cama y subiéndose la ropa hasta la nariz-. Y tampoco vale la pena morir de hambre en este mundo corrompido.

—Pero tú ibas a arreglarlo — alegué cambiándome la ropa mojada-. Cuéntanos tus aventuras y eso de vivir de verdad.

—Eres muy chico para explicarte — dijo desprecioso. 
— ¿Tu verdad es tu barba y tu pelo largo? Si a lo menos me hubieses dejado encontrarte yo...

- ¿Ves que no entiendes nada? Estaba dando una lección a mis padres burgueses y atrasados.

- Pero eso no es arreglar el mundo. Eso es apenitas querer arreglar el tuyo, o sea que te dejen parecer hippie y te dejen no hacer nada...

—iIdiota! ¿Qué sabes tú de los problemas del mundo? (Mi hermano hippie 120).

Marcela Paz publica en 1974 el último libro de la serie, llamado ¿ Soy dix-leso? No hay en el texto ninguna referencia al golpe de Estado de 1973 ni a la situación política del país, pero el niño se involucra en un complejo caso de secuestro y contrabando, acompañando al teniente Albornoz, un carabinero. La imagen del carabinero es de un hombre bondadoso, dedicado a su deber e incluso heroico, que arriesga la vida por detener a los delincuentes, con la ayuda de Papelucho:

—El problema es pillar a los ladrones y devolver el oro a su dueño. Como tú ves la marmicoc guardaba oro que derritió el fuego. Pero los que lo habían guardado ahí van a venir por él. No se atrevieron a sacarlo anoche, por no despertarnos...

— Total es un tesoro ajeno... Podemos dejarlo tirado — dije aburrido.

—Un carabinero tiene obligaciones, Papelucho — dijo mi teni abotonando su chaqueta y poniéndose duro. Pero le dolió algo al enderezarse.

Yo también me puse duro. Un teniente necesita alguien a quien mandar. Apreté mis talones y me achaté las manos en el popi.

— ¡Mande mi teniente! — dije esperando órdenes.

_ ¡Descansa! Ya te diré mi plan cuando lo tenga pensado... (¿Soy dix-leso? 16)

En ese contexto, puede que no sorprenda Esther Huneuus/Marcela Paz recibiera el Premio Nacional de Literatura en 1982, es decir, cuando el gobierno dictatorial solía tener un trabajo arduo buscando un literato que no fuera opositor al régimen autoritario. El jurado dirimió entre ella, el novelista José Donoso y el poeta Miguel Arteche. Hugo Montes, quien fue parte del jurado, habría declarado que: "Eran tiempos muy politizados. . . Miguel [Arteche] tenía más militancia que ahora y al ministro no le gustaba. . . salió el nombre de Marcela Paz y me pareció bien. Era una escritora digna" (Gómez Bravo 291). En el Congreso Mundial de Escritores de 1975 en Niza —a dos años del golpe de Estado y cuando la represión en Chile se encontraba en uno de sus puntos más oscuros- Esther Huneeus asistió, pero habría dicho "perdónenme, yo no vine para hacer política... vengo a hablar en nombre de los niños de Chile" (Gómez Bravo 293). 


\section{Conclusiones}

En la crónica de cuarenta años de la sociedad chilena de Marcela Paz, el término o el concepto clase media no existe. En las palabras de Papelucho, las personas son 'millonarias' o 'pobres', y él mismo y su familia son alternativamente ricos o están 'en la miseria', dependiendo de con quién se relacionen o cuál sea la situación económica puntual de la familia. Proponemos que se trata de una omisión coherente con un imaginario social de raíz colonial y decimonónica donde las personas eran comprendidas como caballeros o rotos y patronas o chinas, sin mayores confusiones; en dicha percepción, los grupos sociales nuevos que crecieron en el siglo XX, como los profesionales, empleados, pequeños y medianos comerciantes y propietarios, no tenían un lugar social ni una definición propia (Candina 20). Esa definición autónoma se construyó paulatinamente en la primera mitad del siglo XX, en términos interpretativos, desde los así llamados intelectuales de la crisis del centenario y los sectores laicos y críticos de una sociedad oligárquica en crisis. Dichos autores generalmente alabaron y relevaron a esa clase media como un grupo diferente o moral y políticamente superior a los sectores populares y a la elite tradicional: se trataba de las personas y familias esforzadas, cultas, ahorrativas y ocupadas de los asuntos públicos, que mejoraban su calidad de vida a partir de su propio mérito y no de un origen privilegiado, y que fueron consideradas la clase-esperanza, en la medida que tenían la educación formal y el espíritu cívico para cambiar Chile y hacerlo más justo y democrático que los más pobres no tenían, y que no arrastraban los defectos de las elites tradicionales, como su cosmopolitismo despectivo y su distancia despectiva de los problemas de los pobres (Barr Melej, Vega).

Valga destacar que la clase media narrada por Marcela Paz no corresponde a esa positiva imagen. Proponemos que Papelucho y su familia pertenecen al poco estudiado grupo de la clase media cuyo origen son los miembros empobrecidos de la clase alta, que fueron descritos en 1950 por Amanda Labarca de la siguiente manera:

El movimiento descendente de los que otrora actuaron en la aristocracia es menos visible, pero no menos cierto. La familia venida a menos oculta tanto tiempo como puede su condición. Valientemente algunas se dedican a faenas productivas que no las rebajan a los ojos de los 'snobs'. Padres y madres se desviven por reabrir a sus hijos las puertas de la educación o de la fortuna que les permitan ocupar de nuevo un alto rango. Mientras tanto, el hecho de su pobreza no les impide suponerse ellos mismos pertenecientes a la aristocracia, ya que los abuelos ocuparon puestos de importancia en la República; pero de hecho vive como clase media (Labarca 81). 
El mundo ficcional que Marcela Paz creó en la década de 1930 y que siguió produciendo y publicando hasta 1974 fue un ambiente de personajes estereotipados y creados para divertir y entretener, pero no pertenecen a una suerte de limbo deshistorizado, ni desde el abordaje lateral y algo taimado que su autora hizo de los cambios y permanencias de la sociedad chilena, ni desde su mirada conservadora y crítica a ellos. Como bien ha descrito David Parker, aun en la década de 1940, "tanto los observadores extranjeros como los locales en su gran mayoría describen la estructura social latinoamericana en términos de dos castas separadas, con una barrera impenetrable entre sî" (Parker 337). Por supuesto, agrega Parker, "esta convención de dos castas herméticas no describe ni lejanamente la sociedad chilena ni otras sociedades latinoamericanas. Algunos apellidos sobrevivieron a lo largo de siglos, pero el grado de rotación de las elites contradice cualquier pretensión de que la gente 'respetable' nace, no se hace” (338). Papelucho y su familia se instalan, en términos sociales, en esa tierra de nadie negada por los imaginarios de los que 'nacen, no se hacen', y que la realidad pone en aprietos continuamente.

Marcela Paz retrató a esa sociedad en transición y tensión, y donde los conflictos de clase y de culturas y subculturas sociales aparecen en casi cada episodio de los relatos. Por una parte, los relatos sobre Papelucho y su familia dan cuenta de esa sociedad tradicional mayoritariamente católica, de nanas puertas adentro, empleados que tratan al niño de patroncito, de tías solteronas y beatas, y más caritativa que crítica. Sin embargo, también son los relatos de las grietas de un mundo social en transformación: el hermano cadete de la Marina se hace hippie, la producción moderna crea nuevos objetos de consumo y de deseo, la ayuda de los parientes 'ricos' no siempre está, o no alcanza. Es una sociedad de nostalgia rural, como la denominó José Bengoa, pero Papelucho ama los automóviles, los viajes en avión, los satélites y teletipos para comunicarse (tal vez e incluso) con otros mundos, e inventa negocios (vende helados, ropa, fotografías, tareas, y hasta su diario: un poco lo que sea) para conseguir 'lucas', como él dice, y comprar lo que quiere.

El primer Papelucho se publicó un año antes de la promulgación de la ominosa Ley de Defensa de la Democracia, en el gobierno de Gabriel González Videla, y la serie siguió adelante a través del período tal vez más esperanzado y apasionado de la política chilena reciente: una época de revolucionarios sin dudas y de conservadores asustados, de inflación incontrolable, de militares conspiradores y marchas obreras masivas, de cine y televisión, de Nueva Canción y hippies. También abordó una época en que la infancia misma, como concepto y proyecto social, se encontraba en plena transformación: desde la década de 1920, la antes ilimitada y legítima autoridad paterna empezó a sufrir reveses ante la intervención del Estado, a partir de las leyes de protección de la infancia desvalida y de instrucción primaria obligatoria. Asimismo, la legitimidad del trabajo infantil, antes poderosamente de- 
fendida por las élites sociales para el caso de los niños de los sectores más pobres, también se encontraba en proceso de disminución y retroceso (Rojas Flores 325). El niño Papelucho, a lo largo de sus aventuras y desventuras, a menudo no entiende a los adultos y sus contradictorias decisiones. Quizás esos adultos, sometidos a un mundo de cambio acelerado, donde los patrones de comportamiento correcto, las definiciones del who's who social y las expectativas y posibilidades del pasado se conservaban y derrumbaban casi al mismo tiempo, tampoco entendían muy bien qué estaba pasando. 


\section{Obras citadas}

Adamovsky, Ezequiel. “Usos de la idea de 'clase media' en Francia. La imaginación social y geográfica en la formación de la sociedad burguesa". Revista Prohistoria, año XIII, número 13, 2009, pp. 9-29.

Barr Melej, Patrick. Reforming Chile. Cultural politics, nacionalism, and the rise of the middle class. Chapell Hill: The University of North Carolina Press, 2001.

Candina, Azun. Por una vida digna y decorosa. Clase media y empleados públicos en el Chile del siglo XX. Santiago de Chile: Editorial Frasis, 2009.

Cosse, Isabella. Mafalda: historia social y política. Buenos Aires: FCE, 2014.

Gómez Bravo, Andrés. El Club de la Pelea. Los Premios Nacionales de Literatura. Santiago de Chile: Ediciones Epicentro Aguilar, 2005.

Labarca Hubertson, Amanda. "Apuntes para estudiar la clase media en Chile". Materiales para el estudio de la clase media en América Latina, volumen VI. Washington DC: Union Panamericana, 1951.

Larraín, Ana María. Marcela Paz: una imaginación sin cadenas. Santiago de Chile: Editorial Universitaria, Santiago, 2009.

López, Ricardo y Barbara Weinstein. "Introduction: We shall all. Toward a transnational history of the middle class". The Making of Middle Classes. Durham: Duke University Press, 2012.

Marcela Paz. Papelucho. Santiago de Chile: Editorial Universitaria, 1947.

_.. Papelucho casi huérfano. Santiago de Chile: Editorial Universitaria, 1951.

__. Papelucho historiador. Santiago de Chile: Editorial Universitaria, 1955.

_.. Papelucho detective. Santiago de Chile: Editorial Universitaria, 1957.

_.. Papelucho en la clínica. Santiago de Chile: Editorial Universitaria, 1958.

__. Papelucho perdido. Santiago de Chile: Editorial Universitaria, 1960.

__. Mi hermana Ji, por Papelucho. Santiago de Chile: Editorial Universitaria, 1964.

_.. Papelucho misionero. Santiago de Chile: Editorial Universitaria, 1966.

_... Papelucho y el marciano. Santiago de Chile: Editorial Universitaria, 1968.

_.. Mi hermano hippie. Santiago de Chile: Editorial Universitaria, 1971.

_.. Papelucho en vacaciones. Santiago de Chile: Editorial Universitaria, 1971.

_.. Papelucho ¿soy dix leso? Santiago de Chile: Editorial Universitaria, 1974

Parker, David. "Siúticos, Huachafos, Cursis, Arribistas, and Gente de Medio 
Pelo: Social Climbers and the representation of class in Chile and Peru: 18601930". The Making of Middle Classes. Editores Ricardo Lopez y Barbara Weinstein, Durham: Duke University Press, 2012.

Rojas Flores, Jorge. Historia de la Infancia en Chile Republicano, 1810-2010. Santiago de Chile: Junta Nacional de jardines Infantiles (JUNJI), 2010.

Vega, Julio. "La clase media en Chile". Revista Occidente, 1950.

Visakovsky, Sergio y Enrique Garguin. Moralidades, economias e identidades de clases medias. Buenos Aires: Editorial Antropofagia, 2009. 